\section{Discurso e mídia: as discursivizações sobre o Piauí nos textos da revista Veja*}

\author{
Discourse and media: the \\ discoursizations about the Piauí \\ in the texts of the magazine \\ Veja
}

Abraão Janderson dos Santos AMARAL (UFPI) abraaojanderson@gmail.com

Raimundo Isídio de SOUSA (UESPI) risidios@yahoo.com.br

Recebido em: 08 de jan. de 2019. Aceito em: 10 de junho de 2019.

*Esta pesquisa foi apresentada em comunicação oral, no XX Congresso da ABRALIN, realizado em Teresina, Piauí, entre os dias 22 e 25 de maio de 2018.

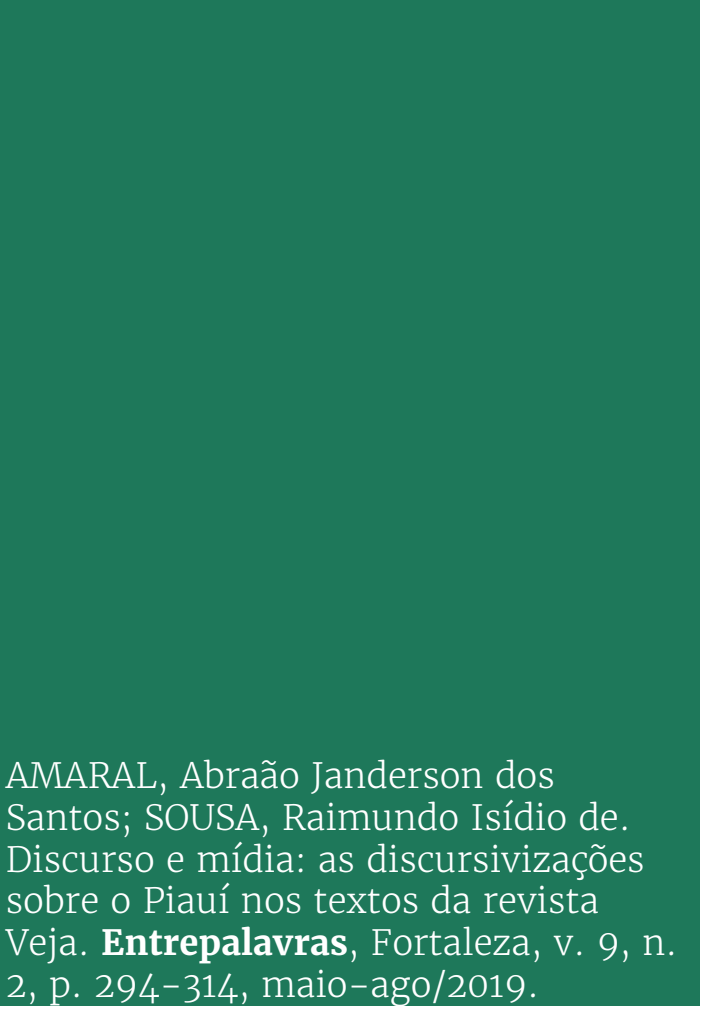

Resumo: Esta pesquisa, fruto de uma monografia, teve o objetivo de analisar as discursivizações sobre o estado do Piauí nos textos que aludem a práticas políticas, presentes nas edições da revista Veja, no período de 2012 a 2017. Optou-se pelos textos da Veja, em função da importância de se compreender como o imaginário social do estado piauiense é construído em textos de circulação nacional. A metodologia da pesquisa enquadra-se como bibliográfica em relação ao objeto, descritiva e interpretativa quanto aos objetivos e de cunho qualitativo, devido à materialidade subjetiva do arquivo e à necessidade de apreensão deste por meio do aparato teórico. Para tanto, foram utilizados pressupostos teóricometodológicos da Análise de Discurso, com base em Pêcheux (2014a; 2014b; 2014c), Pêcheux e Fuchs (2014), Orlandi (2003; 2015) e Mariani (2007; 1996). Verificouse que Veja rearticula uma memória discursiva sobre o estado do Piauí, pela qual são construídos/mobilizados dois movimentos de sentido: os sentidos de generalização e de escassez. Além disso, são observados processos de subjetivação e de alusão ao estado, acionados por Veja, a fim de legitimar seus dizeres acerca de assuntos da política.

Palavras-chave: Revista Veja. Análise de Discurso. Piauí. 
Abstract: This research, resulting from monograph, aimed to analyze the discoursizations about the state Piauí in the texts that allude to the policies practices, present in editions of the magazine Veja, in the period 2012-2017. We chose the Veja texts that refer to Piauí, due to the importance of understanding how the state of the social imaginary is in texts of national circulation. The research methodology is part of literature as to the object, descriptive and interpretative about the objectives and qualitative nature, due to the subjective file materiality and the need for assessment of it through non-numeric theoretical apparatus. Therefore, the theoretical arguments of discourse analisys, based on Pêcheux (2014a; 2014b; 2014c), Pêcheux e Fuchs (2014), Orlandi $(2003 ; 2015)$ and Mariani $(2007 ; 1996)$ were used. It was found that subject rearticulates analyzed one memory discourse on the state of Piauí, through which two movements are reevaluated meanings: the speech of generalization and of scarcity. In addition, processes of subjectivation and allusion to the state are observed, driven by the subject Veja, in order to legitimize his sayings about certain subjects of politics.

Keywords: Magazine Veja. Discourse Analisys. Piauí.

\section{Introdução}

No século XXI, os veículos midiático-informativos, sobretudo os mais reconhecidos, continuam a ter um impacto considerável sobre a sociedade. Notícias e reportagens ocupam cada vez mais o cotidiano da população mundial. Muito se questiona em pesquisas científicas, inclusive, se as mídias têm o poder de influência capaz de derrubar governos, motivar comportamentos, formar opiniões (MAIA; AGNEZ, 2010) e, ao que nos cabe destacar neste trabalho, constituir discursivamente imaginários de um local.

Diante desse contexto, inclui-se a revista Veja, uma das mais influentes do Brasil, que ocupa um lugar de bastante visibilidade para a população. Convém indagar, entretanto, qual o lugar de abordagem do estado do Piauí dentro do contexto nacional trazido pela Veja. E, mais especificamente, a pergunta que foi levantada é a seguinte: como a revista Veja formula discursivamente o estado do Piauí no que se refere ao assunto mais tratado ao se referir ao estado - a política?

Tendo isso em vista, este trabalho objetivou analisar as discursivizações sobre o estado do Piauí nos textos relacionados à política, das edições da revista Veja, no período de 2012 a 2017. Para tanto, foram interpretados os efeitos de sentido subjacentes às discursivizações dos textos, evidenciando-se os aspectos subjetivos inerentes à revista Veja e sua relação com as condições de produção e identificando-se as formações discursivas às quais a Veja estabelece relações de determinação.

A realização desta pesquisa se justifica por diversos motivos. Em relação ao campo científico, na década atual, os trabalhos acadêmicos nas áreas da comunicação e nas áreas da linguagem, sobretudo no que 
V. 9 (2)

$294-314$

maio-ago 2019

diz respeito à Análise de Discurso, têm produzido poucas discussões sobre os discursos sobre o estado do Piauí em meios de comunicação. Em pesquisas prévias, foram encontrados os artigos de Nascimento (2010) ${ }^{1}$, Magalhães e Sousa (2013)² e Marinho (2016)3 , cuja abordagem centra-se nos discursos e representações relativas ao Piauí. As pesquisas citadas analisam os meios de comunicação do próprio estado e compõem, assim, uma parte considerável para as questões de identidade. Porém, é necessário acrescentar um estudo que discorra sobre a representação do Piauí em meios de comunicação de repercussão nacional.

Ao longo do tempo, o estado do Piauí foi sempre marginalizado ou silenciado perante a sociedade como um todo, resultando disso uma cristalização de discursos negativos sobre essa região. É necessário, portanto, conhecer ao máximo como esses discursos são postos em circulação, principalmente no âmbito da mídia, instância que abarca não apenas o embate entre direcionamentos ideológicos, mas também envolvem questões sociais e de identidade.

A pesquisa está dividida em cinco tópicos. No primeiro, são abordados os conceitos a respeito do discurso e da subjetividade, a instituição midiática, a política, bem como sua especificidade nas revistas informativas. No segundo tópico, é explicitada a metodologia da pesquisa. No terceiro, são trazidas as análises e, no último, são feitas as considerações finais acerca dos resultados da pesquisa.

\section{Análise de Discurso e mídia: uma relação política e institucional}

A Análise de Discurso (AD) atua no campo científico, com o intuito de colocar em questionamento os processos de interpretação, demonstrando como se constitui a materialidade dos sentidos. Em função disso, a AD se coloca em oposição a determinadas concepções, segundo as quais a língua e os sujeitos seriam fontes dos sentidos e dados como evidências (FERNANDES, 2007).

\footnotetext{
${ }^{1}$ NASCIMENTO, Francisco Alcides do. Imprensa e imagens: a construção de representações do Piauí e de Teresina através de jornais diários na década de 1970. Revista CLIO, Pernambuco, v.1, n. 28, p. 1-27, 2010.

2 SOUSA, Leila; MAGALHÃES, Francisco Laerte. A narrativa televisiva na negociação de identidades: uma análise do espaço destinado à tradição na cultura piauiense. Comunicologia - Revista de Comunicação e Epistemologia da Universidade Católica de Brasília, Brasília, v. 6, n. 1, p. 75-90, jan./jun., 2013.

${ }^{3}$ MARINHO, JoseanneZingleara. A imagem de desenvolvimento de Teresina nas propagandas políticas jornalísticas de 1930 a 1945.Revista do departamento de história e do Programa de Pós-Graduação em História do Brasil da UFPI, Teresina, v. 5, n. 2, p. 76-89, jul./dez 2016.
} 
A partir de uma posição crítica em relação à constituição dos sentidos, Michel Pêcheux (2014a) traz à luz o discurso. Ao contrário do entendimento comum acerca desse termo - um gênero textual oral de circulação na esfera política -, entende-se, doravante, o discurso como elemento sine qua non dos processos de significação, isto é, um necessário mediador entre linguagem e exterior histórico-ideológico (ORLANDI, 2003).

De acordo com Pêcheux (2014a), as práticas de linguagem adquirem suas significações a partir de uma relação entre o duplo funcionamento lógico-linguístico com aquilo que lhe é exterior e que se materializa no/pelo discurso, sob as condições de produção específicas. Nessa perspectiva, há, primeiramente, a intervenção histórica na língua, que a carrega de significados, trazendo consigo outros dizeres já constituídos. É, nesse sentido, que o discurso "é um objeto sócio-histórico, em que o linguístico intervém como pressuposto" (ORLANDI, 2003, p. 16).

Essa inscrição histórica da língua é, entretanto, alheia aos sujeitos, visto que há um apagamento de sua opacidade, ocorrido a partir da ideologia. É através dela que os funcionamentos institucionais e a linguagem tornam-se claros aos sujeitos, "em apelo a evidências e representações ideológicas" (HENRY, 2013, p. 21). Essa materialidade ideológica, por conseguinte, organiza-se em um complexo de formações distintas entre si, intituladas de formações ideológicas (FI), as quais representam um conjunto de atitudes concretas e imagéticas que ocupam um lugar de conflito dentre as posições de classes na sociedade e operam através do discurso (PÊCHEUX; FUCHS 2014). Devido a essa funcionalidade das FI que se dá por intermédio do discurso, Pêcheux (2014c) assevera que

Poderíamos resumir essa tese dizendo: as palavras, expressões, proposições etc., mudam de sentido segundo as posições sustentadas por aqueles que as empregam, o que quer dizer que elas adquirem seu sentido em referência às formações ideológicas [...] nas quais essas posições se inscrevem (PÊCHEUX, 2014c, p. 146).

O conceito de formação ideológica pressupõe, desse modo, que todo ato de linguagem ocupa um lugar de sustentação ideológica, com o qual os sentidos estão intimamente intricados. Diferentemente da concepção cartesiana de sujeito consciente, o sujeito da AD é, portanto, um sujeito ideológico que assume o seu lugar deixado no vazio dentre as posições de uma determinada formação social (GRIGOLETTO, 2007). 
V. 9 (2)

$294-314$

maio-ago

2019

Sob aquilo que se intitula forma-sujeito, ele assume saberes específicos e toma uma série de posições discursivas, intituladas de posição-sujeito, seja legitimando uma memória discursiva (bomsujeito) ou negando-a (mau-sujeito), seja tomando posição a partir de uma falsa neutralização (dessubjetivação) (GRIGOLETTO, 2007). Em suma, os sujeitos dizem/interpretam aquilo que suas FIs determinam. Pêcheux (2014c), nessa perspectiva, postula que a interpelação ideológica do âmbito do discurso se delineia a partir do mecanismo intitulado Formação Discursiva (FD) definido, pelo teórico, como complexos de sentido que "determinam aquilo que deve e pode ser dito" (PÊCHEUX, 2014c, p. 147). As FD são, portanto, regiões de interpelação subjetiva.

Dessemodo, as FIs determinam os sentidosnos atos delinguagem a partir das FDs, pois estas são pontos específicos do discurso, em que os sentidos se desenvolvem sob processos discursivos de retomadas, dentre os quais se destacam o efeito metafórico e o pré-construído. Esses processos, com efeito, desempenham uma função de continuidade discursiva que não podem suceder-se, senão historicamente. A língua e, especificamente, as formações discursivas, para adquirirem suas significações, devem inscrever-se numa memória constitutiva, intitulada de interdiscurso, no qual os sentidos se encontram formulados e são linearizados no discurso pelo intradiscurso (PÊCHEUX, 2014C).

As formas de manifestação discursivas e subjetivas expostas evidenciam o funcionamento da ideologia e da História sobre a linguagem. Com efeito, esses processos manifestam-se em toda prática de linguagem, o que compreende sua atuação tanto nas relações interpessoais entre sujeitos, quanto nas relações coletivas entre as instituições e o público. Dentre essas modalidades, destacam-se a instituição midiática e a política, que atuam no imaginário social pelo constante retorno à memória discursiva, ora consolidando sentidos, ora os deslocando (MARIANI, 1996).

$\mathrm{Na}$ conjuntura da atual formação social, a instituição midiática, do ponto de vista discursivo e ideológico, constitui um meio institucional pelo qual os sentidos decorrentes dos fatos cotidianos são homogeneizados e estabilizados de maneira evidente aos sujeitosinterlocutores. É nesse sentido que Mariani (2007) entende o papel da mídia não só 
os sujeitos o que ler, fazer, comer, pensar, agir, criticar etc. Está em jogo nos modos de organização dessa agenda uma padronização, uma homogeneização do sujeito (MARIANI, 2007, p. 212).

Mariani (1996) destaca, ainda, outra característica fundamental do discurso midiático, em específico do meio jornalístico: o modo como as mídias tomam discursivamente por objeto aquilo de que se fala, causando o que se chama de "ilusão referencial da linguagem" (MARIANI, 1996, p. 63). Ainda segundo a autora, os discursos que circulam na esfera jornalística possuem o objetivo de descrever/narrar os fatos. Neste aspecto, a ilusão que se efetua na descrição das notícias é a de que o sujeito não se subjetiva discursivamente, fornecendo a aparência de uma neutralidade.

Mariani (1996) acrescenta, assim, o conceito de memória social para tratar do discurso jornalístico. Segundo a autora, a mídia atua na institucionalização de determinados sentidos e, desse modo, contribui para a constituição de uma memória coletiva, composta por evidências ideológicas acerca do real. Essas evidências mobilizadas pela memória, segundo Mariani (1996, p. 35), são construídas a partir de uma "disputa de interpretações" entre diversas formações ideológicas, que resultam na cristalização ou na predominância de interpretações sobre outras.

Em relação ao discurso midiático e o político, ambos se manifestam na atual formação social, isto é, na configuração do sistema de produção capitalista (ALTHUSSER, 1985), de maneiras distintas, porém não dissociadas. Ao passo que o discurso midiático promove uma homogeneização do real e a estabilização de discursos (MARIANI, 1996), o discurso político comporta os conflitos ideológicos, aparentemente velados, e possui ainda a maleabilidade de circular entre as diversas instituições sociais, das quais se destacam a propaganda e a publicidade (PIOVEZANI FILHO, 2007).

Quanto ao conflito decorrente do espaço político, característico da estabilização ou desestabilização, Mariani (1996) observa que ele "representa a polêmica de um espaço discursivo marcado pelos confrontos e antagonismos existentes entre as FDs" (MARIANI, 1996, p. 45). Em outros termos, do ponto de vista discursivo, a política diz respeito a um conjunto de relações de conflito e de poder em prol da hegemonia do espaço da memória social, por meio da constante luta pela cristalização de sentidos e de evidências ideológicas (MARIANI, 1996). 
V. 9 (2)

$294-314$

maio-ago 2019

Nesse movimento de conflito, os sentidos e a memória social podem tanto ser consolidados mediante o discurso como também podem ser desestabilizados por meio do questionamento ou da negação do sentido hegemônico (ORLANDI, 2015). Além disso, a prática política pode se revestir de movimentos de dessubjetivação, nos quais os embates políticos são disfarçados pelo apelo aos conhecimentos científicos ou aos efeitos de neutralidade decorrentes de diversos discursos (PÊCHEUX, 2014C).

Desse modo, entende-se que, na contemporaneidade, as práticas políticas podem estar presentes em todas as atividades cotidianas. O discurso político, desse modo, se faz cada vez mais presente na esfera midiática e sob diversas materialidades: debates políticos transmitidos por TV, jornais impressos, revistas informativas, propagandas políticas etc. Cada uma dessas materialidades, por conseguinte, possui um desdobramento específico na ordem discursiva (PIOVEZANI FILHO, 2007).

No caso das revistas informativas, de modo geral, elas consistem em materiais impressos ou digitais que estabelecem uma relação de grande contato com o público, seja de maneira formal (pesquisas quantitativas) ou informal (cartas e telefonemas), pois seu conteúdo só é garantido mediante assinatura (SCALZO, 2003). Sendo assim, tais revistas se aproximam de públicos específicos e a estes tratam de direcionar conteúdos de maior atratividade, de modo a antecipar seus interesses e projetar suas posições-sujeito, a exemplo de quando "revista trata o leitor por você, fala com ele diretamente e, às vezes, com intimidade" (SCALZO, 2003, p. 37).

Apesar de as revistas terem o objetivo de alcançar diversos leitores, elas possuem um público-alvo, que mensalmente assina pelo seu conteúdo. E considerando-se que haja múltiplas disponíveis no mercado, "toda e qualquer revista traz consigo uma gama de significados. Ela fala para um público específico, assuntos específicos de uma realidade específica" (GONÇALVES, 2009). Assim, nos processos de produção e na recepção do conteúdo de cada revista, estão envolvidos processos subjetivos que marcam ideologicamente as práticas discursivas de cada mídia informativa.

Partindo dessa perspectiva de apreensão dos processos discursivos pelo entendimento das práticas institucionais midiáticas e políticas, foram feitas análises de como se configuram as discursivizações da revista Veja sobre o Piauí e seus modos de abordagem do imaginário piauiense. Com efeito, a próxima seção descreve todo o processo metodológico para a realização das análises desta pesquisa. 


\section{Processo metodológico de análise}

Com base nos pressupostos da Análise de Discurso, foram feitas as análises que se seguem, a fim de apreender as discursivizações sobre o Piauí nos textos relacionados à política publicados na revista Veja entre 2012 a 2017. Quanto à fonte dos dados, esta pesquisa classifica-se como bibliográfica, uma vez que os discursos são suscitados a partir dos textos contidos em edições já disponibilizadas. Em relação ao objetivo, trata-se de uma pesquisa descritivo-interpretativa, pois exige descrição e interpretação de reportagens da revista em questão. Já em relação à abordagem do objeto estudado, a pesquisa enquadra-se como qualitativa, devido às necessárias interpretações ancoradas nos referenciais teóricos.

Como critério de inclusão das fontes, a escolha da revista Veja deu-se pelo seu grande alcance no Brasil, tendo uma média de 1.205.086 leitores até o segundo mês do ano de 20174 . Em se tratando da escolha do período de cinco anos para apreender o objeto pretendido, numa quantificação prévia acerca das publicações da Veja no século XXI, constatou-se que a revista deixou de publicar textos sobre o estado durante nove anos, uma lacuna entre 2003 e 2012. Mesmo que essa lacuna seja significativa, esta pesquisa permaneceu no limite de considerar o arquivo discursivo (PÊCHEUX, 2014b) disposto entre o ano de 2012, época em que finda a ausência de publicações, e 2017, ano em que foi realizada a presente pesquisa.

Tendo em vista os objetivos, a coleta de dados deu-se por meio do acesso ao acervo da Veja disponibilizado no site da editora Abril. A partir de uma seleção feita pela ferramenta de busca, foi realizado o recorte que se constituiu apenas das revistas que citaram o nome "Piauí" e seus derivados. Quanto à escolha do tema da política, observou-se que, dentre as 67 edições que trazem o nome Piauí, no período de 2012 a 2017, 31 revistas tratam do tema da política.

Tendo em vista que não se pode expor toda a pesquisa nos limites estabelecidos, optou-se somente pelas reportagens referentes à relação entre Piauí e o Partido dos Trabalhadores (PT). Esse recorte justifica-se devido ao fato de 16 reportagens, das 31 analisadas, terem tratado de tal assunto. Por fim, foi feita a subdivisão de 3 movimentos discursivos feitos pela Veja, dos quais serão trazidos apenas 2, devido às reportagens sobre o PT terem se direcionado a tais sentidos: o da generalização e o da escassez.

${ }^{4}$ Dados oficiais do Instituto Verificador de Circulação (IVC). 
V. 9 (2)

$294-314$ maio-ago 2019

\section{A revista veja e os sentidos de generalização}

O primeiro grupo de análise é composto por 9 textos, dos quais são trazidos apenas 3, em que o estado do Piauí é citado na superfície linguística, compondo a generalização de fatos políticos. No primeiro texto de tal natureza discursiva, é trazida uma notícia da cidade de Miguel Leão, localizada no interior do Piauí. Segundo a notícia intitulada Teste de popularidade, no período de eleições da região, o prefeito Jailson de Sousa, aliado do governo do PT, fez uma campanha eleitoral com o auxílio da figura política do ex-presidente Lula.

A revista destaca principalmente o fato de que, nesse mesmo município, Lula obteve $87 \%$ dos votos da população nas eleições de 2006, uma vitória significativa. Porém, mesmo o ex-presidente fazendo um vídeo de apoio ao candidato petista da cidade, a população não teve a mesma adesão à sua influência nas eleições suplementares realizadas no mês de agosto, de 2017. Assim, a revista Veja relaciona este acontecimento eleitoral com o fato de Lula ter sido condenado e investigado:

Figura 1 - Texto Teste de popularidade

MIGUEL LEÃO, no interior do Piaui, tem 1516 eleitores e menos de 100 quilômetros quadrados. Apesar do tamanho da cidade, a política por ali não difere muito da dos grandes centros. Em 2016, o prefeito Joel de Lima, aliado do governador petista Wellington Dias, foi reeleito com $53 \%$ dos votos. Um ano depois, seu mandato foi cassado pela Justiça. Motivo: o entẫo candidato participara da inauguração đe uma obra pública durantea campanha, o que é proibido. No domingo 6,0 leoninos voltaram às urnas para escolher o novo alcaide, entre Roberto César, do PR, candidato de oposição, e o petista Jailson de Sousa, que contou com a ajuda de um caboeleitoral poderoso Luiz Inácio Lula da Silva, que, no pleito
Inacio Lula da Silva, que, no pleito presidencial de 2006 , levou $87 \%$ dos votos no municipio.

O apoio de Lula era considerado decisivo, eoex-presidente atése $\mathrm{cm}$ penhou. Num video de trintasegundos enviado ao celular dos moradores da cidade, Lula fez umapelo aos eleitores: "O גailson é do PT, e você sabe que oPT sabe govemar o Brasil, sabe governar Miguel Leão. Por isso, no domingo, não se esqueça, vote em Jailson". Abertas as urnas, a surpresa: o petista Jailson, o favorito, perdeu. "As pessoas sabem que Lula não é maiso santo que elas imaginavam", comemorou Roberto César, o vitorioso. Foi o primeiro teste da força eleitoral de Lula depois de sun condenaçẫo à prisî̃o. E o resultado nẫo se mostrou muito animador. Para ele. 
Neste enunciado, nota-se a menção ao fato não esperado: apesar da aparente adesão que se tinha ao presidente Lula, a população de Miguel Leão seguiu o lado oposto da expectativa, votando no opositor do candidato que foi apoiado pelo ex-presidente ("Abertas as urnas, a surpresa: o petista Jailson, o favorito, perdeu"). Com efeito, este fato encaminha a forma-sujeito ${ }^{5}$ a retomar outras condições de produção, a prisão de Lula ("Foi o primeiro teste da força de Lula depois de sua condenação à prisão"), e, em consequência disso, retoma sentidos e relações lógicas de causa e consequência que, conforme a formação discursiva da Veja, estão claramente relacionados. Nesse caso, há a ocorrência de um deslizamento de sentidos na medida em que um acontecimento no interior do Piauí leva à retomada de outro, mediado pela interpelação ideológica da forma-sujeito.

No limiar das condições de produção do enunciado, a formasujeito, que ocupa o lugar discursivo e institucional de jornalista, toma sua posição-sujeito na forma-sujeito do saber jornalístico e utiliza-se dos saberes desta, que são decorrentes do interdiscurso. O deslizamento de sentido feito pela Veja, que relaciona o contexto piauiense ao contexto do ex-presidente Lula, é decorrente de sua interpelação à formação discursiva que lhe determina ou a que se filia. Observa-se, pois, que o fato ocorrido não é trazido à tona coincidentemente, já que seus sentidos dão margem para uma relação de causa e consequência: os eleitores do Piauí não votaram no candidato do PT, porque este recebeu o apoio de Lula, que, por sua vez, foi condenado.

Essa antecipação da revista pode ser observada no título "Teste de popularidade" e na proposição destacada anteriormente, mostrando como se busca deixar implícitas essas marcas de sentido. Além disso, o fato de haver a evocação de outro contexto - as eleições de 2006 -, bem como o fato de o sujeito utilizar de frases como "abertas as urnas, a surpresa" ou de ocultar outros motivos que pudessem ter levado as eleições àquele resultado - por exemplo, a cassação do ex-prefeito aliado -, evidencia um percurso subjetivo empreendido para destacar um fato peculiar do estado para formular hipóteses generalizadas acerca de um fato político.

No recorte seguinte, constata-se a presença de uma situação semelhante à anterior, quanto aos esquecimentos. Na coluna de J. R. Guzzo, com o título Ideia Fixa, a forma-sujeito questiona a hipótese

\footnotetext{
${ }^{5}$ Emprega-se, doravante, o conceito forma-sujeito para se referir à forma-sujeito do saber jornalístico. Quando, por ventura, houver a presença de outra forma-sujeito do discurso, esta será definida integralmente.
} 
V. 9 (2)

$294-314$ maio-ago 2019 de que os cortes nos gastos do governo prejudicariam os mais pobres, usando-se de argumentos e exemplos para desconstruir tal ideia. Entre os exemplos citados, a forma-sujeito se refere ao interior do Piauí para ironizar a premissa sustentada por um sujeito outro, segundo a qual não se pode diminuir a capacidade de investimento do Estado brasileiro:

Figura 2 - Fragmento do texto Ideia fixa

\begin{tabular}{|l|}
\hline relho de segurança pública, que conse- \\
gue manter os casos de homicidio em \\
apenas 60000 por ano. Também não \\
se pode, asseguram os campeões do \\
pró-gasto, diminuir a "capacidade de \\
investimento do Estado brasileiro" - \\
talvez a melhor piada de todas, consi- \\
derando-se que o Estado brasileiro, há \\
anos, não tem dinheiro para investir \\
nem na construção de um mata-burro \\
no interior do Piauí. Gasto público, ain- \\
\hline
\end{tabular}

Fonte: Revista Veja. ed. 2521, n. 11, mar. 2017.

Conforme visto no fragmento acima, a forma-sujeito faz uma crítica aos "campeões pró-gasto", isto é, àqueles que são contra os cortes no setor público. Utiliza-se, pelo intradiscurso, o discurso direto e das aspas a fim de distanciar-se do discurso outro, que defende a manutenção da capacidade de investimento do Estado brasileiro (Também não se pode, asseguram os campeões pró-gasto, diminuir a 'capacidade de investimento do Estado brasileiro'), e, logo após, refuta os sentidos decorrentes dessa ideia, referindo-se a esta como "talvez a melhor piada de todas", uma vez que, no interior do Piauí, não teria dinheiro para investir em simples demandas, como na construção de um mata-burro - mecanismo semelhante a uma ponte que impede a fuga de animais bovinos.

Assim como no texto anterior, o mecanismo discursivo de substituição contextual, o efeito metafórico, é trazido no intradiscurso de maneira condicionada para constituir os sentidos decorrentes da formação discursiva da Veja, visto que sua ação na retomada de sentidos, "o deslize - próprio da ordem do simbólico - é lugar da interpretação, da ideologia, da historicidade" (ORLANDI, 2003, p. 80). No trecho "não tem dinheiro para investir nem na construção de um mata-burro no interior 
do Piauí", a historicidade e as posições ideológicas materializam-se pelo direcionamento da forma-sujeito às condições do interior piauiense, como exemplificação de algo sem detalhes adicionais, em função da necessidade de consolidar os próprios sentidos.

Considerando que há diversos contextos relacionados à falta de investimento no setor público, a forma-sujeito poderia ter evocado outros exemplos de lugares com falta de investimento e ter escolhido múltiplas formas de formalizar seu enunciado para ir de encontro à ideia refutada. Porém, novamente a partir dos esquecimentos $n^{0} 1$ e $n^{0}$ 2, deixa-se de lado todas as outras formas e direciona-se o enunciado a uma memória generalizante acerca do Piauí. Ao mesmo tempo, a alusão a uma condição atípica no interior do estado e o uso das formas linguísticas negativas e redundantes em "não tem dinheiro para investir nem" ressaltam o efeito de esquecimentos lógico-linguísticos que concretizam as discursivizações sobre a incapacidade estatal e marcam o discurso sobre o fato exótico no interior do Piauí.

Assim, a menção ao imaginário piauiense decorre apenas de maneira secundária e como suporte para a sustentação de um argumento acerca de uma prática política, contra a qual o sujeito se opõe, colocandose como mau sujeito em relação ao discurso antagônico (GRIGOLETTO, 2007). Nesse contexto, mesmo que as significações sejam mediadas por um sujeito-enunciador, este se manifesta no interior da revista como porta-voz do sujeito institucional, demonstrando, pois, a materialidade da formação discursiva da revista Veja e sua tendência a cristalizar uma memória social específica sobre o Piauí.

Na reportagem intitulada Sem porta de saída, é evidenciada a situação dos habitantes contemplados pelo programa social Bolsa Família, especialmente na região Nordeste do país. A forma-sujeito faz uma abordagem quantitativa dos dados e interpreta-os a fim de mostrar os fatores negativos e positivos do programa social. Ao longo do texto, busca-se confirmar a hipótese de que devido à expansão do programa Bolsa Família os habitantes de baixa renda têm-se tornado cada vez mais dependentes da assistência. Além disso, é trazida a premissa de que o programa proporciona um "retorno político imenso". Para confirmar suas análises, a forma-sujeito faz um recorte da população do país contemplada pelo programa. Salvo um exemplo da região paulista, são citados casos e comentários apenas de habitantes do Nordeste, bem como estatísticas do número de beneficiados pela assistência em estados como Piauí e Maranhão: 
v. 9 (2)

294-314 maio-ago 2019
Figura 3 - Fragmento do texto Sem porta de saída (leitura no sentido horário)

Os cidadãos que recebem a mesada
federal veem Lula como o responsável
pelos repasses de dinheiro. "Foi por cau-
sa do Lula que eu parei de depender dos
meus pais e consegui alugar uma casi-
nha", diz Evanilde Santos da Silva,
piauiense de 32 anos, moradora de Se-
bastião Barros, a 840 quilometros de
Teresina. A americana Wendy Hunter,

FILA DO CAIXA Em Sebastião Barros, no Piaut, como $90 \%$ da população é dependente do programa, o dinheiro costuma acabar antes do meio-dia

Fonte: Revista Veja. ed. 2339, n. 38, set. 2013.

Os dados e as informações são trazidos, portanto, no sentido de confirmar as hipóteses da reportagem, sem que se considerem outras hipóteses ou informações. Percebe-se, na reportagem, um condicionamento de sentidos decorrente da interpelação da Veja. Sendo assim, a Veja aceita para si uma evidência acerca dos impactos do Bolsa Família na política e na produtividade dos beneficiados, que é defendida não só na reportagem referida, mas nas matérias seguintes (Figuras $5 \mathrm{e}$ 6), figurando uma relação de sentidos respectivos a uma determinada FD.

No decorrer da reportagem, o estado do Piauí é citado duas vezes como exemplo, primeiramente por meio de um comentário de uma moradora e em seguida por meio de uma imagem dos habitantes da cidade fazendo fila para receber o auxílio. Abaixo da imagem, é apresentada a estatística de que $90 \%$ da população da cidade recebe o Bolsa Família e, além disso, é trazida a informação de que "o dinheiro costuma acabar antes do meio dia", por conta da dependência do programa. A forma-sujeito não especifica onde o dinheiro costuma acabar, quantos locais para fazer saque de dinheiro existem na cidade e nem em quais ocasiões - apenas no dia do recebimento ou em todos os dias - o dinheiro acaba antes do meio dia. Essas omissões dão margem à interpretação dos sentidos da continuidade.

Quanto à segunda premissa - o Bolsa Família proporciona um retorno político no momento de eleições -, a forma-sujeito utiliza-se do comentário de uma moradora da cidade do Piauí, introduzido por meio do discurso direto, para confirmar o exposto. Na fala de Evanilde Silva, ela afirma que foi por causa de Lula que ela conseguiu alugar uma 
casa e deixar de depender dos pais. Assim, a negociação do discurso de um sujeito outro que confirma, por meio da experiência, a relação entre o auxílio e o ex-presidente Lula, suscitando um efeito de veracidade do fato formulado.

Após a evocação do interdiscurso relacionado à forma-sujeito da experiência cotidiana, a forma-sujeito jornalística ainda retoma os dizeres de um sujeito que ocupa o lugar discursivo de especialista. A americana Wendy Hunter, especialista em governos latino-americanos e autora de um livro sobre essa temática, é citada na matéria também pelo nível do intradiscurso sob a forma de discurso direto e traz os resultados de um estudo feito em três municípios do Nordeste. A pesquisadora afirma que o auxílio está muito atrelado à imagem de Lula, o que sustenta a hipótese levantada na reportagem sobre o benefício político decorrente.

\section{A revista veja e os sentidos de escassez}

Nesta seção, são analisados os sentidos da escassez na retomada do imaginário piauiense, em 11 reportagens das quais se destacam 3 pelo critério já exposto. A reportagem seguinte intitula-se 0 mito da nação dividida ao meio e foi publicada no ano de 2014, especificamente no período de encerramento das eleições presidenciais. Na época, a disputa eleitoral estava sendo decidida no segundo turno e acabou culminando na vitória de Dilma Rousseff, do PT, sobre o adversário Aécio Neves, do Partido da Social Democracia Brasileira (PMDB). Na reportagem, a revista destaca a reviravolta do PT no momento crucial da disputa e o crescimento do partido de Aécio, defendendo a premissa de que houve um crescimento da polarização política entre os eleitores. Porém, o enfoque principal é dado para contrariar a hipótese de que o Brasil se divide geograficamente no momento de votação, afirmando que a motivação maior é a questão socioeconômica. Para confirmar sua hipótese, a forma-sujeito utiliza-se de estatísticas e cita como exemplo o estado do Piauí: 
V. 9 (2)

$294-314$

maio-ago

2019
Figura 4 - Fragmentos do texto 0 mito da nação dividida ao meio.

\begin{tabular}{l}
\hline complexa enuançada: o eleitorado não se \\
divide pela geografla, com sulistas de um \\
lado e nordestinos de outro, mas pela si- \\
tuação socioeconômica. Por isso, Aécio, \\
embora bem votado nas áreas ricas e \\
avançadas, também tem votos no Piaul, \\
ainda que poucos. Pela mesma razão, \\
Dilma, candidata dos rincões pobres, tem \\
votos em Santa Catarina, poucos, mas \\
tem. Resume Lavareda: "Năo se trata de \\
um apreço setentrional ao PT ou uma \\
aversão meridional ao PT".
\end{tabular}

Os bolsões petistas

No semiárido do Piaúi e no norte do Maranhão, Dilma obteve suas melhores votaçōes. As duas regiōes são pobres, compostas de pequenos vilarejos e 0 alvo primordial das políticas sociais do governo, sobretudo o Bolsa Familia. Mesmo assim, com população escassa, as cidades assinaladas com vermelho mais intenso, somadas, não the deram mais do que $\mathbf{1 5 0} \mathbf{0 0 0}$ votos

Fonte: Revista Veja. ed. 2398, n. 45, nov. 2014.

Após apresentar os votos na região piauiense e maranhense, a forma-sujeito adverte sobre a escassez dos estados, ressaltando a pobreza e trazendo a evidência da relação de causa e consequência entre votar no PT e ser dependente de programas sociais como o Bolsa Família. No decorrer da matéria, a forma-sujeito chega a afirmar que a melhor explicação para o número de votos do PT na região Nordeste é decorrente das políticas públicas de auxílio, o que demonstra o seu alto grau de engajamento com uma formação discursiva antipetista. $\mathrm{Na}$ proposição em destaque, há inclusive a expressão "Os bolsões petistas" no intuito de ressaltar essa evidência.

A partir de dados e de relações de causa e consequência, a forma-sujeito se dessubjetiva pelo viés do conhecimento técnico e estabelece a seguinte evidência: os estados que são pobres e que se beneficiam de programas sociais tendem a votar no PT ("As duas regiões são pobres, compostas de pequenos vilarejos e alvo primordial das políticas sociais do governo, sobretudo, o bolsa família"). Tem-se, portanto, um efeito de generalização simbólico-ideológico mediado pela revista Veja. Na matéria, um acontecimento complexo e disperso, que é a adesão do público a partidos políticos, é explicado e homogeneizado em uma reportagem.

Todo o percurso de tornar as discursivizações homogêneas por intermédio das práticas científicas não seria possível senão pela recorrência a uma memória discursiva, que traz consigo elementos implícitos marcados ideologicamente por representações de uma determinada formação ideológica. Nesse sentido, o discurso tecnicista permite consolidar tal elemento discursivo e produzir o efeito de verossimilhança na reportagem, mesmo que a Veja continue no interior de sua formação discursiva. 
Ademais, a recorrência às práticas científicas permite que a forma-sujeito se coloque criticamente ante às práticas políticas. Ao defender a tese de que a motivação principal dos eleitores em escolher um candidato é decorrente do fator socioeconômico, a forma-sujeito enuncia que "Aécio, embora bem votado nas áreas ricas e avançadas, também tem votos no Piauí". Analisando esse recorte discursivo, é possível identificar um pré-construído acionado pelas formas "embora" e "também". O enunciado antecipa ao leitor a interpretação de que apesar de Aécio ter recebido muitos votos nas regiões $X$, que seriam ricas e avançadas, ele também recebeu votos na região piauiense, que seria escassa ou atrasada.

No recorte seguinte, o mesmo movimento de sentido de relacionar o PT com o programa Bolsa Família e os sentidos da escassez piauiense manifestam-se em uma pequena coluna. Em um quadro constando o cenário da disputa eleitoral para governador do Piauí, aparecem os dois concorrentes, Wellington Dias (PT) e José Filho (PMDB), e a previsão de que o primeiro deveria ganhar as eleições já no primeiro turno. Abaixo da previsão, no tópico o que está em jogo, a revista esclarece o porquê do peso eleitoral demonstrado pelo candidato petista, qual seja por conta do programa Bolsa Família que, segundo a revista, atende a $48 \%$ dos piauienses.

Figura 5 - Cenário eleitoral

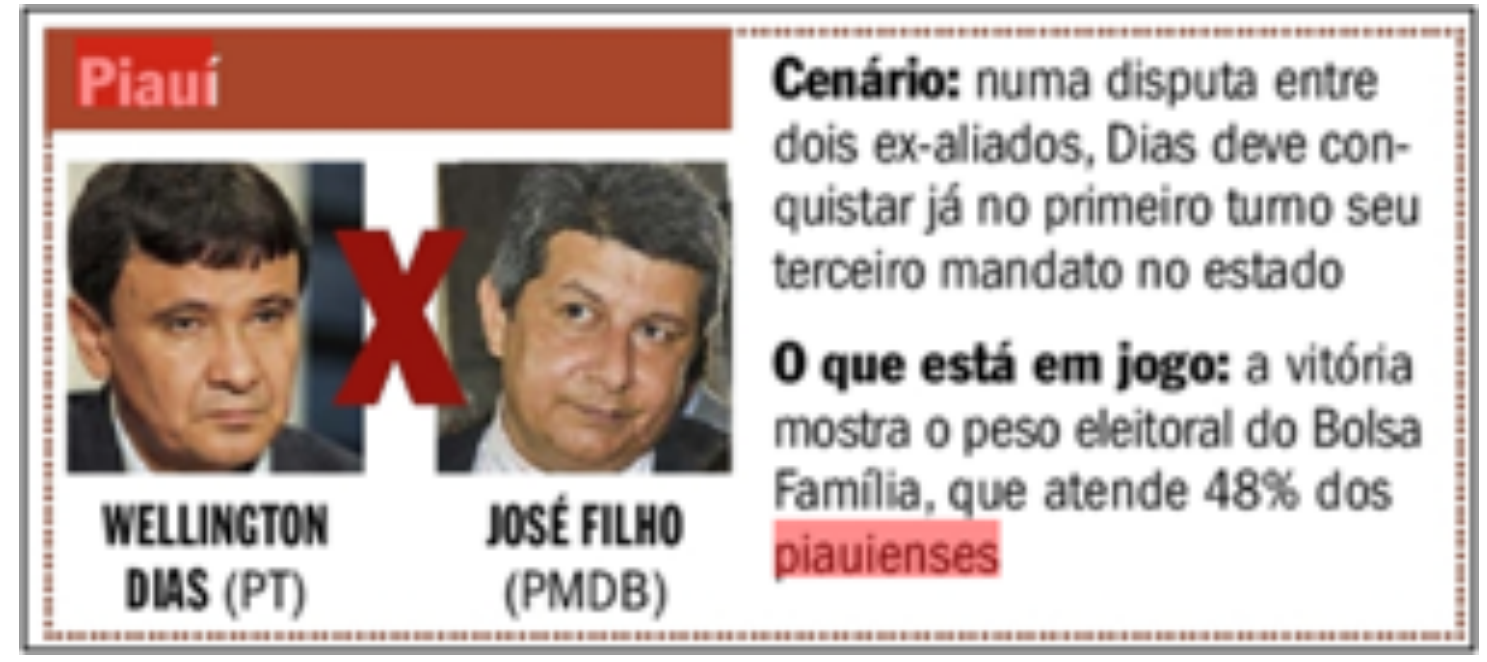

Fonte: Revista Veja. ed. 2394, n. 41, out. 2014.

A forma-sujeito é novamente interpelada a fazer uma conexão entre a adesão do público piauiense ao candidato do PT e o fato de serem dependentes do programa Bolsa Família. Percebe-se que, no caso da revista Veja, essa interpretação do acontecimento 
V. 9 (2)

$294-314$

maio-ago 2019 político no Piauí é naturalizada de tal modo, que seus sentidos são evocados como evidências, deixando-se de lado outras interpretações para o fato - a conjuntura política do estado ou as diferenças entre campanhas, por exemplo. Por meio da interpelação da forma-sujeito à sua formação ideológica, ele é levado a recusar a opacidade do acontecimento e resumi-lo num sentido lógico consolidado. Mediante essa naturalização ideológica, ignoram-se, na notícia, outros sentidos em detrimento dos pré-concebidos, de modo que a Veja não precise ao menos justificar a relação entre o peso eleitoral do candidato petista e o fato de $48 \%$ da população receber a assistência do Bolsa Família; apenas coloca-se a evidência no fio do seu discurso.

Considerando as constantes retomadas dessa evidência pela Veja, verifica-se uma construção discursiva mediada por uma memória que se faz hegemônica nos dizeres da revista, a saber: a maioria dos eleitores do estado do Piauí tenderá a votar em candidatos petistas por conta da dependência da população ao programa Bolsa Família. Essa evidência não só é repetida diversas vezes pela revista, como também é materializada sob um mantra de naturalidade, que é um efeito ideológico.

A revista Veja, por conseguinte, reforça um dos papéis da mídia na atual formação social, definido por Mariani (1996): o de contribuir na estabilização de interpretações, constituídas num conglomerado de relações de força. E considerando que todas essas construções discursivas foram contextualizadas em um momento de eleições governamentais, outro papel das mídias se realiza a partir das discursivizações da Veja: participar na consolidação ou na dissolução de sentidos antagônicos, decorrentes do conflito partidário.

Esse efeito de evidência discursiva é também trazido pela revista Veja na próxima reportagem, sob o formato entrevista, publicada em outubro do mesmo ano, com o título O Nordeste não é do PT. O entrevistado chamado Marcus André Melo responde a uma série de perguntas relacionadas às eleições presidenciais e às estatísticas de voto. Em suma, o cientista político afirma que não existe relação de fidelidade entre o eleitor e um determinado candidato, mas, sim, uma relação de benefícios, em que o eleitor se pauta para fazer sua escolha. Desse modo, o entrevistado cita o estado do Piauí como exemplo, destacando a relação entre a suposta precariedade do estado e a aderência ao partido do PT. 
A forma-sujeito novamente traz o imaginário de escassez do estado, através da mesma relação entre pobreza e direcionamento político (nas áreas economicamente desfavorecidas [...] o que existe é um comportamento de adesão a qualquer governo vigente, justamente devido à dependência que a população dos grotões do Brasil guarda...). Nos recortes trazidos anteriormente, Veja consolida, em sua linguagem, uma memória discursiva que preserva imagens e representações ideológicas do espaço regional piauiense como lugar de condição precária. Para realizar este efeito de sentidos, ora a forma-sujeito ocupa duas posições-sujeito, de especialista e de jornalista, ora utiliza-se de elementos do interdiscurso ou até mesmo de especialistas para legitimar seus discursos.

Figura 6 - Fragmentos do texto O Nordeste não é do PT.

No Piaui, Dilma levou $70 \%$ dos votos, o seu melhor desempenho estadual. Segundo o cientista politico pernambucano Marcus André Melo, contudo, não se pode definir a região como petista. Professor da Universidade Federal de Pernambuco (UFPE), com Ph.D. na Universidade de Sussex, na Inglaterra, e pós-doutorado no Instituto de Tecnologia de Massachusetts (MIT), Melo observa que, nas áreas economicamente desfavorecidas, não há uma fidelidade mecânica ao partido. $\mathrm{O}$ que existe é um comportamento de adesão a qualquer governo vigente, justamente devido à dependência que a população dos grotōes do Brasil guarda em relação às politicas públicas. Qualunquismo é a

\section{0 que explica a clara preferência da} maioria dos eleitores de São Paulo ao PSDB? Meu próximo livro, que deve ser lançado no ano que vem pela Universidade de Princeton, nos Estados Unidos, analisa justamente os dois valores primordiais na política atual: a inclusão e a estabilidade econômica. No Piauí, a preocupação é a inclusĩo. No Sudeste, há mais empresas, o setor privado é mais forte. É um cenário em que as questōes macroeconômicas ganham mais peso, e o PSDB tem reputação mais sólida nesse aspecto. Não estou dizendo que todo eleitor do PSDB seja um eximio conhecedor de contas públicas. Mas a agenda de preocupaçōes já é outra. Tenho muitas

Fonte: Revista Veja. ed. 2395, n. 42, outubro. 2014.

No caso da entrevista, é inserida pelo intradiscurso a voz do cientista político a partir do discurso direto, exterior ao enunciado, a fim de se distanciar ou de consolidar os efeitos de sentido evocados pelo outro. Assim, as palavras do especialista são inscritas diretamente na entrevista, no intuito de que as discursivizações pertencentes à mesma formação discursiva da Veja causem efeitos diferenciados em seus sujeitos-leitores.

Nesse caso, os sentidos mobilizados pelo especialista assemelham-se com os dizeres da Veja. Ambos defendem que a situação socioeconômica condiciona os eleitores a escolher determinados candidatos e citam, igualmente, o estado do Piauí como exemplo. Nas 
V. 9 (2)

$294-314$

maio-ago 2019

falas do cientista político, além da revista, há constantemente um interesse em delimitar sua posição-sujeito. Quando perguntado sobre a preferência dos eleitores de São Paulo pelo PSDB, o sujeito especialista menciona primeiramente o iminente lançamento de seu livro acerca do assunto perguntado: "meu próximo livro, que deve ser lançado no ano que vem pela Universidade de Princeton, nos Estados Unidos, analisa...". Essa forma introdutória de formular o seu dizer é um simulacro de sua aparente liberdade subjetiva que, na verdade, aponta para o seu assujeitamento a uma FD, sob a posição-sujeito do discurso científico.

Desse modo, Veja retoma um sujeito especialista, que ocupa um lugar discursivo no interior da forma-sujeito do saber científico e que reconhece as determinações ideológicas que o colocam em tal posição. Tais determinações foram constituídas na atual formação social a partir de relações de força formadas no limiar da história, que se encontram além do sujeito especialista. Interpretam-se, pois, as palavras do especialista, que busca, a todo momento, marcar sua posição-sujeito, mas também se filia à mesma FD da revista, aquela que tende a relacionar o Piauí aos sentidos da carência e, consequentemente, os eleitores do Piauí ao PT.

\section{Considerações finais}

À guisa das considerações finais, verificou-se que a revista Veja se filia a uma rede de enunciados que trazem consigo os sentidos da generalização e da escassez, dentre outras filiações histórico-ideológicas negativas acerca do estado piauiense. Apesar de, em nenhum momento, o Piauí ser o tema principal das discursivizações de Veja, o imaginário do estado é, de modo geral, retomado como recurso argumentativo de exemplificação e da antecipação, como elemento de sustentação de opiniões políticas. As formas de alusão a discursos cristalizados na memória social, característicos do discurso midiático, irrompem os enunciados analisados e corroboram, portanto, a institucionalização de sentidos negativos.

Em relação aos objetivos que guiaram a realização desta pesquisa, foram observadas formas de a revista estabelecer gestos de interpretação sobre acontecimentos e fatos a partir de relações de sentido condicionadas ideologicamente. Ademais, foi constatada a presença de modos de subjetivação empreendidos pela forma-sujeito do saber jornalístico, ora passando para o lugar de pesquisador ora para o lugar 
do público. Todos esses movimentos subjetivos e discursivos levam Veja a discursivizar conforme uma formação discursiva antipetista, reforçando efeitos de sentidos atinentes ao imaginário de um Piauí generalizado em relação à escassez de recursos econômicos e quanto à dependência de políticas públicas dos governos petistas.

\section{Referências}

AUTHUSSER, Louis. Aparelhos Ideológicos de Estado: nota sobre os aparelhos ideológicos de Estado (AIE). 2. ed. Rio de Janeiro: Edições Graal, 1985.

FERNANDES, Cleudemar Alves. Análise do discurso: reflexões introdutórias. 2. ed. São Carlos: Claraluz, 2007.

GONÇALVES, Maxlander Dias. Veja: uma história do PT e do primeiro governo Lula sob a ótica das notícias. 2009. 234 f. Dissertação (Mestrado em História Social das Relações políticas) - Universidade Federal do Espírito Santo, Centro de Ciências Humanas e Naturais, Espírito Santo. 2009.

GRIGOLETTO, Evandra. Do lugar social ao lugar discursivo: o imbricamento de diferentes posições-sujeito. In: Seminário de Estudos em Análise de Discurso, 2, 2005, Porto Alegre, RS. Anais eletrônicos do II SEAD - Seminário de Estudos em Análise do Discurso. Porto Alegre: UFRGS, 2007.

HENRY, Paul. A ferramenta imperfeita: língua, sujeito e discurso. Trad. Maria

Castro. 2. ed. Campinas, SP: UNICAMP, 2013.

MAIA, Kênia Beatriz Ferreira; AGNEZ, Luciane Fassarella. O agenda-setting no Brasil: contradições entre o sucesso e os limites epistemológicos. Revista da Associação Nacional dos Programas de Pós-Graduação em Comunicação/ E-compós, Brasília, v. 13, n. 3, p. 1-16, set./dez. 2010.

MARIANI, Bethania Sampaio Corrêa. o comunismo imaginário: práticas discursivas da imprensa sobre o PCB (1922 -1989). 1996. 256 f. Tese (Doutorado em Linguística) - Universidade Estadual de Campinas, Instituto de Estudos da Linguagem, Campinas, SP. 1996.

Imprensa, produção de sentidos e ética. In: RIBEIRO, Ana Paula; FERREIRA, Lucia Maria (Org.). Mídia e memória: a produção e sentidos nos meios de comunicação. Rio Branco: Mauad, 2007. p. 199-217.

ORLANDI, Eni Orlandi. Análise de Discurso: princípios e procedimentos. 4. Ed. Campinas, SP: Pontes Editores, 2003.

. Maio de 1968: os silêncios da memória. In: ACHARD, Pierre; DAVALLON, Jean; DURAND, Jean-Louis; PÊCHEUX, Michel; ORLANDI, E. P. papel da memória. 4. Ed. Campinas, SP: Pontes Editores, 2015. p. $53-56$.

PÊCHEUX, Michel. Análise Automática do Discurso (AAD-69). In: GADET, Françoise; HAK, Tony. (Org.). Por uma análise automática do discurso: Uma introduçăo à obra de Michel Pêcheux. Campinas: Editora da Unicamp, 2014a. p. 59-158. 
V. 9 (2)

$294-314$ maio-ago 2019
Ler o arquivo hoje. In: ORLANDI, Eni Orlandi (Org.). Gestos de leitura: da história no discurso. ed. 4. Campinas, SP: Editora da Unicamp, 2014b. p. 57-67.

Semântica e discurso: uma crítica à afirmação do óbvio. 5. ed. Campinas, SP: Editora da Unicamp, 2014c.

PÊCHEUX, Michel; FUCHS, Catherine. A propósito da análise automática do discurso: atualização e perspectivas (1975). In: GADET, Françoise; HAK, Tony. (Org.). Por uma análise automática do discurso: Uma introdução à obra de Michel Pêcheux. Campinas: Editora da Unicamp, 2014. p. $159-250$.

PIOVEZANI FILHO, Carlos. Metamorfoses do discurso político contemporâneo: por uma nova perspectiva de análise. Revista da ABRALIN, v. 6, n. 1, p. 25-42, jan./jun. 2007.

SCALZO, Marília. Jornalismo de revista. São Paulo: Contexto, 2003.

VEJA. São Paulo: Editora Abril, ed. 2543, n. 33, ago. 2017

. São Paulo: Editora Abril, ed. 2521, n. 11, mar. 2017.

. São Paulo: Editora Abril, ed. 2398, n. 45, nov. 2014.

VEJA. São Paulo: Editora Abril, ed. 2394, n. 41, out. 2014.

. São Paulo: Editora Abril, ed. 2339, n. 38, set. 2013. 